This manuscript has been accepted in Disability and rehabilitation. Assistive technology. Please see: "Macnamara, A., Chen, C. S., Davies, A., Sloan, C., \& Loetscher, T. (2021). Low vision devices for age-related macular degeneration: a systematic review. Disability and rehabilitation. Assistive technology, 1-13. Advance online publication. https://doi.org/10.1080/17483107.2021.1966523"

\title{
Low Vision Devices for Age-Related Macular Degeneration: A Systematic Review
}

Anne Macnamara, BPsy(Hons), ${ }^{1}$ Celia S. Chen, PhD,${ }^{2}$ Andrew Davies, BASc, ${ }^{3}$ Charlotte Sloan, ${ }^{1} \&$ Tobias Loetscher, $\mathrm{PhD},{ }^{1}$

${ }^{1}$ Cognitive Ageing \& Impairment Neurosciences Laboratory, UniSA Justice \& Society,

University of South Australia, Adelaide, Australia

${ }^{2}$ College of Medicine and Public Health, Flinders Medical Center and Flinders University, Adelaide, Australia

${ }^{3}$ Royal Society for the Blind, Adelaide, Australia

Corresponding author.

Anne Macnamara

Email: anne.macnamara@mymail.unisa.edu.au

Postal address: Campus Central - Magill, University of South Australia, St Bernards Road, Magill SA 5072 


\begin{abstract}
Purpose: Age-related macular degeneration (AMD) is a degenerative condition impacting central vision. Evaluating the effectiveness of low vision devices provides empirical evidence on how devices can rehabilitate and overcome deficits caused by AMD. This evidence could help to facilitate discussion on necessary future improvements to vision enhancement technology.
\end{abstract}

Methods: A systematic review of the literature was conducted on low vision devices use in AMD populations. Relevant peer-reviewed research articles from six databases were screened.

Results: The findings of thirty-five studies revealed a significant positive impact of low vision devices leading to improvements in visual acuity, reading performance, facial recognition, and more. While the studies were found to have moderate risks of bias, a GRADE assessment of the evidence suggested the certainty of the evidence was lowmoderate.

Discussion: Simple hand-held low vision devices (e.g., magnifiers) appear to currently have greater preferential support than newer visual enhancement technology (e.g., head mounted devices). Financial, comfort or usability reasons may influence preferences more than performance-based findings. However, there is a lack of studies examining newer technologies in AMD populations, which future research should address. Moreover, given the presence of bias across the studies and limited controlled experiments, confidence in the results may be low.

Conclusions: Most studies indicated that low vision devices have positive impacts on reading and visual performance. But, even though they are reported to be a valuable asset to AMD populations, more rigorous research is required to draw conclusive evidence. 
Keywords: Low vision devices, age-related macular degeneration, visual impairment, quality of life, rehabilitation 
Affecting approximately 200 million people globally, age-related macular degeneration (AMD) leads to visual impairment and can cause irreversible central vision loss $[1,2]$. The burden of vision impairments is significant, with direct and indirect economic costs that amount to billions of dollars associated with AMD within Australia alone [3,4]. Investigating strategies and interventions to effectively rehabilitate and manage AMD are of high importance to the visual impairment community, especially with an increasingly aging population.

\section{Consequences of Age-Related Macular Degeneration}

Age-related macular degeneration is a progressive degenerative eye condition, characterised by the deterioration of the retina. Early AMD is caused by subretinal drusen, small yellow or white lipid products. As it evolves into later stages, choroidal neovascularisation may occur, in which blood vessels grow under and leak fluid and blood into the macula [5]. Visual symptoms of AMD manifest in a variety of ways, leading to difficulties in areas such as reading, computer use, driving, and recognising faces $[6,7]$.

Severe AMD can make reading a single word almost impossible without vision enhancement [8]. Impaired abilities to perceive faces and recognise emotions in facial expressions are linked to reduced quality of life and social engagement, because people with AMD lose confidence in detecting social nuances and become concerned about offending their acquaintances [7]. There is also a heightened risk of falls and injury due to declining hazard detection [9]. These factors, and more, can contribute to increased depression and anxiety [10,11]; as well as an overall effect on all manner of physical, social and psychological domains [12,13].

\section{Managing Age-Related Macular Degeneration}

The management of AMD includes medical and supportive approaches. There are two forms of AMD, dry (non-exudative) versus wet (exudative). There is no medical treatment 
for dry AMD and the management is supportive. In wet AMD, selected cases may be suitable for medical treatment with anti-vascular growth factor intravitreal injections, that aim to slow the progression of the disease and vision loss [5,14], but the treatment cannot revert vision to a pre-diagnosis state. Supportive care with low vision devices is therefore a fundamental part of management to optimise activities of daily living. Low vision devices have existed in varying forms for decades (e.g., magnifiers, electronic visual enhancement systems, etc.) and can have a substantial impact on improving outcomes for people with AMD [15].

There are other types of supportive care, such as alternative illumination, ergonomic adjustments, rehabilitation and education programs, as well as mobility aids. The combination of these multidisciplinary approaches is important to the long-term management of AMD. However, the interest in low vision devices is because devices can directly manipulate the image formed on the retina. The cost of low vision devices can vary dramatically, from free apps, to cheaper magnifiers (AUD\$20), and expensive electronic devices (AUD\$5,000) [16]. Depending on the level of support required, buying low vision devices may be a larger financial investment compared with making environmental or lifestyle changes. For example, upgrading home lighting can significantly improve a visually impaired person's quality of life [17]. Yet, this is a comparatively inexpensive change relative to the thousands of dollars required to purchase more expensive low vision devices. Empirical evidence of the benefits of low vision devices for AMD populations is important when considering the cost at stake.

\section{Specifications of Low Vision Devices}

The primary function of many low vision devices is enhancing the retinal image of objects in the visual field [18]. While traditional low vision devices (e.g. hand magnifiers) have been indispensable to the visually impaired community, they are limited in their capabilities due to fixed magnification levels and restricted field of views [19,20]. Newer low 
vision devices have the digital processing technology to instantly manipulate the retinal image of the immediate visual field through contrast, luminance, colour correction, remapping, and spatial frequency filtering [20,21]. Despite these innovations, this is only the start of what modern low vision devices could become, as eye-tracking technology and augmented reality devices are also being integrated [20].

Low vision devices have previously been evaluated on visual acuity, functionality, usability, and cost $[20,22]$. Participants in a recent study comparing low- and high- priced head-mounted devices reported that the high-priced device provided better visual experiences, quality and comfort [22]. Yet, participants concluded that they would still purchase the low-priced alternative, because they could not justify the price in exchange for the difference in image quality [22]. Thus, research into low vision devices does need to take into consideration that cost-effectiveness and suitability are relative to the individual.

\section{Outcomes of Interventions}

Successfully managing AMD should ensure that interventions are improving physical, social and psychological domains, in addition to enhancing vision [6,23]. Improvements in reading smaller print do not necessarily equate to the individuals' wellbeing. Hence, research into low vision devices should integrate vision assessments with measures of emotional experience, subjective experience, and quality of life. Previous systematic reviews have collated literature on low vision devices and interventions for AMD [24]. However, their relevance and significance are somewhat constrained due to more recent advances in low vision technology.

Recent reviews on AMD have focused on specific domains or outcome measures, like depression, quality of life, or reading performance [25-27]. However, comprehensive reviews on many outcome measures can be more informative for the visually impaired community. For instance, Binns et al. [28] reviewed the literature on visual impairment rehabilitation 
services, by examining quality of life, health and mood, on top of clinical visual assessments. As such, this review aims to expand on previous systematic searches into low vision devices, by evaluating all outcomes investigated, instead of focusing on specific measures. We intend to provide a more recent and comprehensive analysis of the benefits of low vision devices for people with AMD.

\section{Methods}

Preferred Reporting Items for Systematic Reviews and Meta-Analyses (PRISMA) has been followed [29]. The review was not prospectively registered. A systematic search was conducted to identify all studies featuring the use of low vision devices in AMD populations. The following search strategy was used (see Appendix A for the full database strategy): "Macular degeneration" AND ("Adaptive technolog*" OR aid* OR "assistive technolog*" OR "augmented realit*" OR beacon* OR computer* OR device* OR "head mount*" OR magnif* OR "mediated realit*" OR "mixed realit*" OR phone* OR sensor* OR "smart technolog*" OR tablet* OR "virtual realit*").

Papers were included in the review if they investigated the use of devices that could enhance vision within participants with a primary diagnosis of age-related macular degeneration. Eligible papers were required to include at least one measure of the effect the device had on the participants (e.g., vision related, subjective response). They could include participants with other vision conditions (e.g., Glaucoma or Cataract) if there was a separate AMD group or outcome measure reported, or at least $75 \%$ of the participant group had a primary diagnosis of AMD. Exclusion criteria included non-experimental studies, non-peer reviewed publications (e.g., conference articles, dissertations); case studies <5 people; AMD populations with subsets of comorbid conditions (e.g. Stargardt's disease); or participants that had medical treatment or surgery (e.g., implants or prosthetics) during the study although a history of either was accepted. 
The search was conducted on August 16th, 2019 (followed by an updated search on May 9th 2020) via Ovid, by simultaneously searching five databases: Embase Classic+Embase, Ovid Emcare, Ovid MEDLINE ® All, Ovid Nursing Database, and PsycINFO. This was accompanied by a search in IEEE Xplore, using only the search term "Macular degeneration". As this database comprises recent research on advancements in technology, electronics and computer science, it complemented the five medical and alliedhealth related databases. Given the prestige of conference presentations in technology-related fields of research, conference proceedings indexed in IEEE Xplore were accepted for inclusion in this review. All other inclusion and exclusion criteria were adhered to.

Screening was managed with Covidence systematic review software. Title and abstract screenings were conducted by a single reviewer, based upon the pre-agreed selection criteria. A subsequent full-text screening was undertaken independently by two reviewers. A consensus between reviewers was required for papers to be included in the final synthesis. Conflicts on eligibility were discussed, and if a consensus was not reached, a third reviewer was consulted. Eligible studies were then examined, and relevant data extracted. The data includes what researchers evaluated in their studies (e.g., reading performance, appraising rehabilitation programs); what devices were utilised (e.g. closed-circuit televisions, magnifiers); the measures and tests employed (e.g. vision assessments, self-report questionnaires); as well as what researchers found (e.g. what effect did the low vision devices have on the measures and tests?). This information was agreed upon by two reviewers prior to data extraction. Data extraction was completed by a single reviewer and checked by a second reviewer. Throughout this process, the second reviewer was consulted when there was ambiguity over relevant data.

The Joanna Briggs Critical Appraisal Tools for Quasi-Experimental Studies (nonrandomised experimental studies) was used to evaluate the studies' methodological quality 
[30]. Two researchers appraised the articles based on a checklist of nine questions, and disagreements were settled through discussion. The study was classed as having a "high" risk of bias if it met less than $49 \%$ of the criteria, a "moderate" risk if it met between $50-69 \%$ of criteria, and a "low" risk if it adhered to $70 \%$ or more of criteria. Inter-rater reliability was calculated to assess the consistency of the appraisals using the Cohen's Kappa method and interpreted as expressed in McHugh [31].

Furthermore, the certainty of the evidence was examined using GRADE (Grading of Recommendations, Assessment, Development and Evaluation) [32] - this process was, in part, guided by a GRADE algorithm [33]. "High quality" indicates that authors are confident the true effect is similar to the estimated effect; "moderate quality" is the true effect is probably close to the estimated effect; "low quality" means the true effect might be markedly different from the estimated effect; and "very low" suggests the true effect is probably markedly different from the estimated effect.

\section{Results}

The systematic search originally identified 5,443 articles (see figure 1), with a further 347 new articles revealed in the updated search. After title, abstract and full-text screenings, just 35 articles met the inclusion and exclusion criteria. Appendix B presents the full data on demographics, study purpose, types of devices, measures and tests, findings, risk of bias, and sources of funding and support for each study.

\section{Critical Appraisal}

Overall, the studies employed methodology that had a moderate risk of bias.

Appendix $\mathrm{C}$ presents the individual assessments made by each reviewer, followed by the final agreed criteria decision. Cohen's Kappa revealed a moderate level of agreement $(k=0.63)$. Approximately $12 \%$ of checklist responses were "Unclear", due to not enough information being provided in the papers to make definitive judgements about the criteria. As such, the 
risk of bias may be higher or lower. This was particularly evident for criteria three, wherein reviewers agreed it was not explicitly clear in over half of the studies whether participants received treatment other than the low vision device - a factor which may have affected outcomes. Also, almost all the studies lacked control groups (criteria four) - only four studies were randomised control trials [34-37]. While within-group designs are common in this field of research, the internal validity of the studies might be biased.

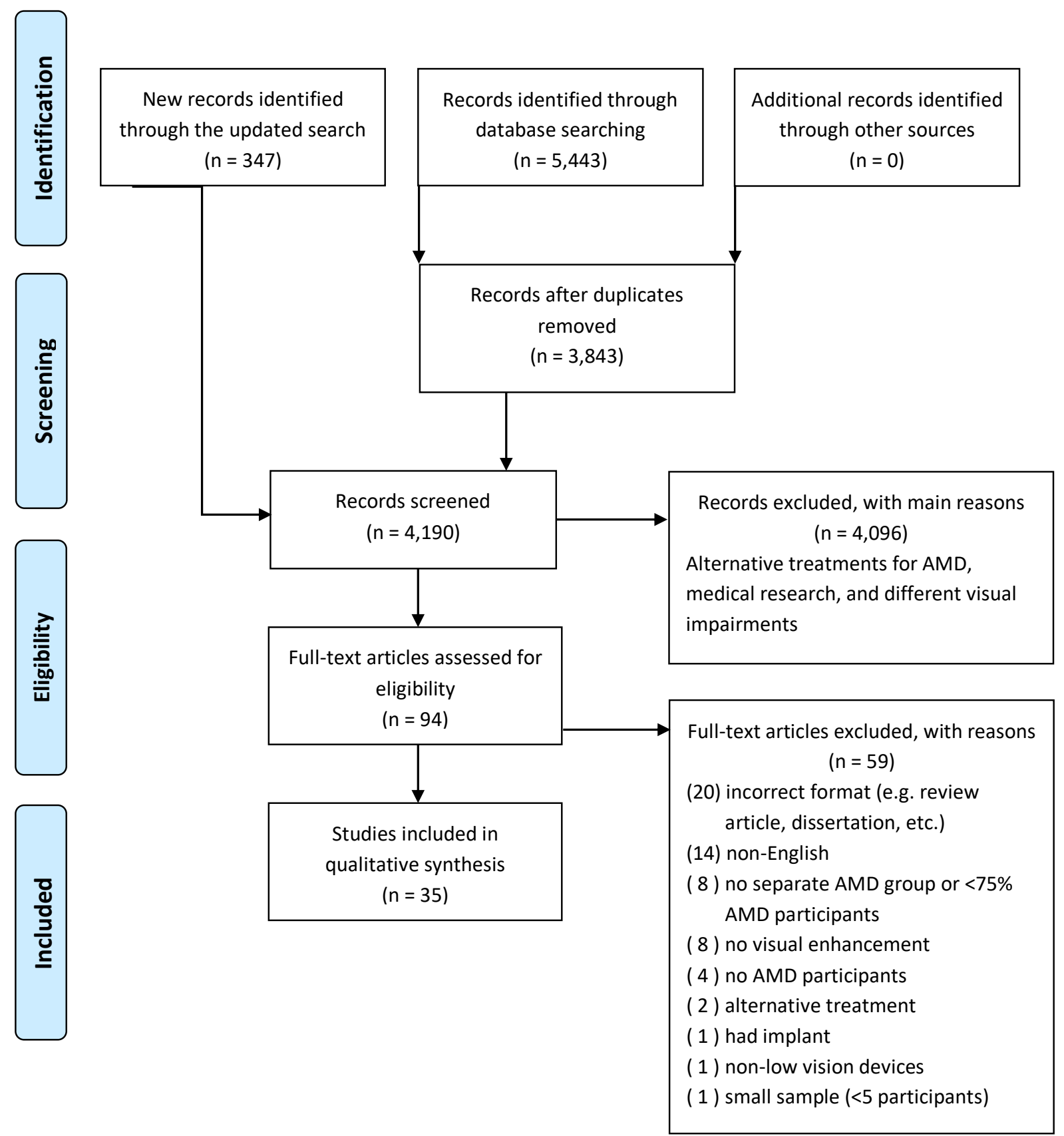

Figure 1. PRISMA flow diagram for low vision device studies in macular degeneration populations. 


\section{Purpose of the Studies}

One of the primary aims of over half (54.3\%) of the studies was to evaluate reading ability in AMD populations, with approximately $77.1 \%$ of studies including at least one reading performance measure. Most study protocols began with a vision assessment before proceeding to the relevant tasks under investigation. Twelve facets of AMD and low vision devices were explored by researchers (see figure 2), including the effects of rehabilitation and training programs, evaluating magnification requirements for low vision devices, as well as examining facial and emotional recognition abilities.

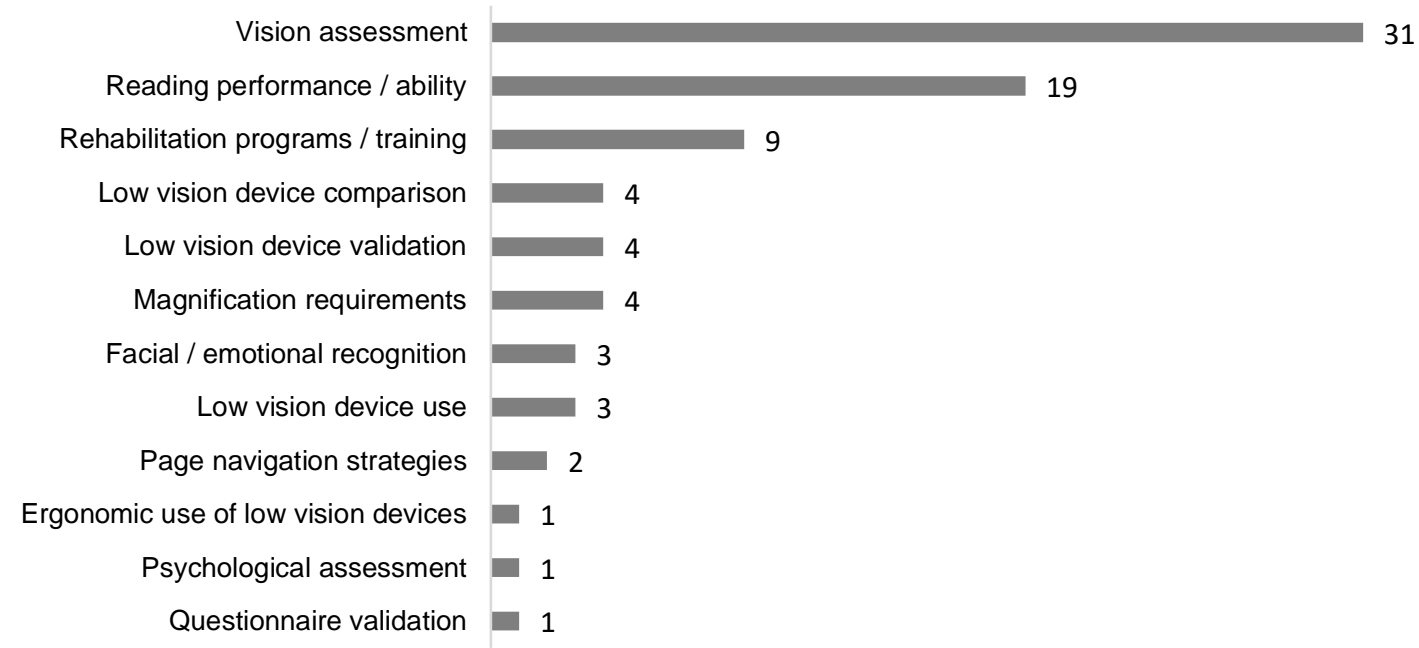

Number of Studies

Figure 2. Purpose of age-related macular degeneration research by category.

\section{Types of Low Vision Devices}

Figure 3 depicts the distribution of low vision devices as assigned by category.

Magnifiers were the most prevalent devices tested $(n=50)$. Glasses and / or spectacle-based devices $(n=27)$, closed-circuit televisions $($ CCTV $)(n=13)$, and telescopic devices $(n=$ 13) were the next most commonly tested. A small number of electronic reading devices $(\mathrm{n}=$ 7) and head-mounted devices $(\mathrm{n}=7)$ were examined, e.g., iPad and NuVision respectively, in addition to simple other devices such as a dome and microscope. For the full description of the low vision devices investigated, see Appendix D. 
Given the proportion of magnifiers, this category can be partitioned further. This includes illuminated and non-illuminated stand $(\mathrm{n}=19)$ and hand magnifiers $(\mathrm{n}=17)$; and other formats $(\mathrm{n}=14)$ such as bar, distance, flat-field, lamp, neck, pocket, spectacle, and optical magnifiers. But, if the magnifiers category were to be redefined to any device that enhances vision or content for the user, the number of "magnifiers" would increase to an estimated $86.6 \%$ of all devices assessed.

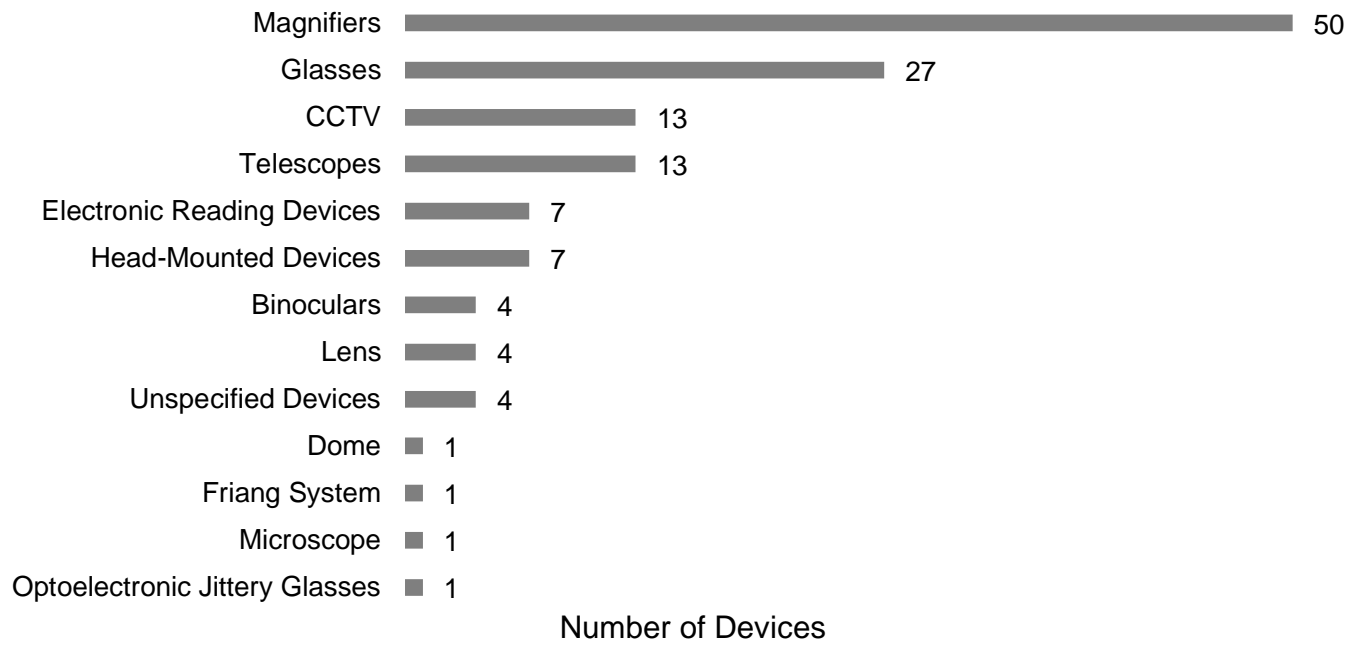

Figure 3. Low vision devices categories.

\section{Measures and Tests}

Vision assessment

Vision assessment was a fundamental measure in almost all studies. ETDRS ( $\mathrm{n}=11)$, Bailey-Lovie distance letter $(n=6)$, MNRead $(n=6)$, and Bailey-Lovie near word $(n=5)$ were the most used charts to assess visual acuity. all presenting rows of progressively smaller letters and words for participants to read. Other forms $(n=5)$ included the MonoyerGranstrom Kifa letter chart and the E-scale (see table 1 for all vision acuity charts). Contrast sensitivity was another standard assessment in twelve studies. The Pelli-Robson chart $(\mathrm{n}=$ 10) was frequently administered, where participants read letters from rows as the contrast between the letters and background gradually decreased. Further clinical aspects of vision 
that were evaluated include fixation, microperimetry, scotoma size, and more. See Appendix B for more details.

Table 1. Charts used to assess visual acuity in age-related macular degeneration populations.

\begin{tabular}{lcc}
\hline Visual acuity charts & Num of studies & References \\
\hline ETDRS & 11 & Ferris et al. (1982) [38] \\
Bailey-Lovie (distance) & 6 & Bailey and Lovie (1976) [39] \\
MNRead & 6 & Mansfield et al. (1993) [40] \\
Bailey-Lovie (near) & 5 & Bailey and Lovie (1976) [39] \\
Unspecified & 4 & NA \\
GP & 3 & Preisler, Malmö, Sweden (1995) [41] \\
Snellen & 3 & Snellen (1862) [42] \\
E-Chart & 1 & Snellen (1862) [42] \\
Lea-Symbol & 1 & Hyvärinen (1980) [43] \\
LogMAR & 1 & Bailey and Lovie (1976) [39] \\
Monoyer-Granstrom Kifa & 1 & Monoyer (1872) [44] \\
Topcon Projector & 1 & Topcon (2018) [45] \\
\hline
\end{tabular}

Seven studies used multiple visual acuity charts.

NA: not applicable

\section{Reading performance}

Different components of reading performance $(n=27)$ were examined: reading accuracy, acuity, duration, speed, rate, and critical print size. Standardised text passages and reading assessments are the preferred mediums to appraise these measures, e.g., the MNRead $(n=7)$, International Reading Speed Tests $(n=3)$, and Bailey-Lovie text charts $(n=2)$.

Studies $(n=6)$ would also incorporate text from real everyday items, e.g., newspapers, bills, grocery lists. As listed in table 2, of the 27 studies that included a measure of reading performance, there were 17 types of materials. 
Table 2. Materials used to assess reading performance in age-related macular degeneration populations.

\begin{tabular}{lcc}
\hline Testing materials & Num of studies & References \\
\hline General / unspecified text & 7 & NA \\
MNRead chart & 7 & Mansfield et al. (1993) [40] \\
Real items (e.g. medicine bottles, newspaper print) & 6 & NA \\
International Reading Speed Tests & 3 & Trauzettel-Klosinski and Dietz (2012) [46] \\
Lighthouse cards \& chart & 3 & Silverstone et al. (2000) [47] \\
Bailey-Lovie chart & 2 & Bailey and Lovie (1980) [48] \\
Jaeger's chart & 2 & Jaeger (1856) [49] \\
Maclure children reading book & 2 & Maclure (1980) [50] \\
Oxford Progressive English Readers & 2 & Oxford University Press (2020) [51] \\
Sloan reading cards & 2 & Sloan and Brown (1963) [52] \\
Times New Roman chart & 2 & Sussex Vision (2020) [53] \\
Uni of Waterloo test card & 2 & Bailey (1986) [54] \\
Chinese reading card & 1 & Wu et al. (1991) [55] \\
English Radner Reading Chart & 1 & Radner et al. (1998) [56] \\
Gray Oral Reading Test & 1 & Wiederholt and Bryant (2001) [57] \\
Morgan Low Vision Reading Comprehension Assessment & 1 & Watson and Wright (1996) [58] \\
Neale Analysis of Reading Ability & 1 & Neale et al. (1999) [59] \\
\hline
\end{tabular}

Eight studies used multiple test materials.

NA: not applicable

\section{Self-report questionnaires and tests}

Thirteen studies used self-report questionnaires and tests to assess AMD participants on health domains: cognition, depression, general health, quality of life, and vision. Only five self-report questionnaires and tests, the Manchester Low Vision Questionnaire $(n=3)$, Mini Mental Status Exam $(\mathrm{n}=3)$, National Eye Institute Visual Function Questionnaire $-25(\mathrm{n}=$ 3), Geriatric Depression Scale $(n=2)$, and Visual Analog Scale $(n=2)$ were administered across multiple studies. All others were used once (see table 3 for all the self-report questionnaires and tests).

The Mini Mental Status Exam, Montreal Cognitive Assessment and Ocular Health Assessment were questionnaires only administered as part of eligibility screenings to assess the participants' cognition and health status. The Activity Inventory, Manchester Low Vision Questionnaire, Visual Analog Scale, and Vision Function Index were instruments used to measure subjective feelings and attitudes from participants regarding satisfaction, difficulties, comfort and ease of use with their respective low vision devices and tasks. 
Table 3. Self-report questionnaires and tests used to assess age-related macular degeneration domains.

\begin{tabular}{llc}
\hline $\begin{array}{l}\text { Age-related macular degeneration domains } \\
\text { Types of questionnaires / tests }\end{array}$ & Num of studies & References \\
\hline $\begin{array}{l}\text { Cognition } \\
\text { Mini Mental Status Exam }\end{array}$ & 3 & Folstein et al. (1975) [60] \\
$\quad \begin{array}{l}\text { Montreal Cognitive Assessment } \\
\text { Short Portable Mental Status Questionnaire }\end{array}$ & 1 & Nasreddine et al. (2005) [61] \\
Pfeiffer (1975) [62]
\end{tabular}

Seven studies used multiple self-report questionnaires and tests.

\section{Subjective feedback}

Subjective feedback from participants was examined in thirteen studies by directly asking participants about their feelings and experiences of AMD and low vision devices. A combination of rating and Likert scales $(n=8)$, and general questions evaluated this $(n=5)$.

Example questions and statements are presented below:

"Which did you find easier to use? Handheld CCTV / Stand-mounted CCTV / No preference". Goodrich \& Kirby p. 524 [76]

"I have difficulty recognising familiar faces in the street. Disagree strongly - Agree strongly". Tejeria et al. p. 1020 [77]

"How useful did you find the eccentric fixation point to aid reading the text? Not useful - Very useful”. Walker et al. p. 464 [78] 


\section{Findings}

\section{General outcomes}

As presented in table 4, researchers found significant positive effects of low vision devices on vision, reading performance, depression, quality of life, and face recognition. The use of low vision devices was highly valued, perceived as useful, or improved a relative outcome measure in 33 studies. Of the other two studies, one reported no statistical differences between participant outcomes with and without a low vision device [79], and the other did not investigate differences in outcomes with and without low vision devices [80]. Generally, measures of vision and reading ability were significantly improved in most studies (moderate quality evidence). All three studies assessing facial and emotional recognition found significant gains in recognition ability with a low vision device (very low quality evidence) $[77,81,82]$.

Table 4. Outcome measures investigated in age-related macular degeneration populations.

\begin{tabular}{|c|c|c|c|c|}
\hline Outcome measures & Num of studies & Reported findings $^{a}$ & Overall evidence & 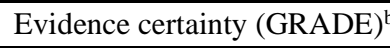 \\
\hline \multicolumn{5}{|l|}{ Vision-related outcomes } \\
\hline Objective assessments: i.e. visual acuity & 31 (4 RCTs) & $\uparrow--\downarrow$ & $\uparrow$ & Moderate \\
\hline Reading performance & 27 (3 RCTs) & $\uparrow--\downarrow$ & $\uparrow$ & Moderate \\
\hline $\begin{array}{l}\text { Subjective responses: i.e. self-report } \\
\text { visual function questionnaires }\end{array}$ & $7(1 \mathrm{RCT})$ & $\uparrow--\downarrow$ & - & Low \\
\hline Face recognition & 3 & $\uparrow--\downarrow$ & $\uparrow$ & Very low \\
\hline Task performance: i.e. writing & 2 & $\uparrow--\downarrow$ & - & $\bigcirc$ Low \\
\hline \multicolumn{5}{|l|}{ Beyond vision outcomes } \\
\hline Depression & $4(1 \mathrm{RCT})$ & $\uparrow--\downarrow$ & - & Low \\
\hline Quality of life & $4(2 \mathrm{RCT})$ & $\uparrow--\downarrow$ & - & Low \\
\hline General health & $2(1 \mathrm{RCT})$ & $\uparrow--\downarrow$ & - & Low \\
\hline Cognition & 1 & $\uparrow--\downarrow$ & - & Low \\
\hline
\end{tabular}

RCT: Randomized control trial

a Direction: $\uparrow=$ significant positive effects reported; $--=$ effects not reaching significance reported; $\downarrow=$ significant negative effects reported

${ }^{\mathrm{b}}$ GRADE: High quality = authors are confident the true effect is similar to the estimated effect; Moderate quality = the true effect is probably close to the estimated effect; Low quality = the true effect might be markedly different from the estimated effect; Very low quality $=$ the true effect is probably markedly different from the estimated effect 
The questionnaires revealed limited significant improvements because of low vision devices and interventions. Only one study found significantly lower symptoms of depression and anxiety after the provision of a low vision device [83]. A different study reported a positive psychosocial impact of low vision devices after a month of use, however this finding did not reach significance [84]. Likewise, most studies reported no significant changes to health domains related questionnaires (low quality evidence). One study did find significantly deteriorated scores on the Vision Core Measure and the Short Form Health Survey at a twelve-month rehabilitation follow-up - although this was accompanied by a significant decrease in visual acuity [37].

Subjective feedback from participants provided varied opinions on the experience, ease of use and preferences for different low vision devices $[71,76]$. For example, the majority of an AMD group reported a range of difficulty levels using a magnifier, yet they still used magnifiers multiple times each day [71]. Another participant group rated magnifiers as moderately to extremely useful for reading mail, bills and for leisure [85]. Some studies reported that reading was easier with newer low vision devices (e.g., Epson Moverio BT-200) compared to standard methods $[78,86]$, whereas others showed that printed paper was the easiest medium to read from [87]. Researchers have suggested that financial considerations and personal characteristics of people with AMD may be significantly influence preferences for low vision devices [76].

However, as indicated in table 4 , the evidence certainty was generally low to moderate, therefore the real impact of low vision devices may differ from that estimated within the studies. The evidence was consistently downgraded due to risks of bias at trial and review quality level, as well as varying precision of sample sizes. These judgements were made in consideration of the lack of randomisation in the studies' designs, and the moderate risks of bias exhibited by the methodological approaches. 


\section{Rehabilitation and training}

Rehabilitation and training programs had a positive impact on outcome measures in eight studies (low quality evidence) [34,41,82,88-91]. Greater benefits may be derived from low vision devices if skill development sessions are provided $[41,82,91]$. Through a randomised control trial, Nilsson highlighted that these benefits were even better when formal training programs are administered rather than basic instructions [36]. A multidisciplinary approach, with a combination of low vision device and rehabilitation services (i.e. eccentric viewing training, counselling, education) was also more likely to increase quality of life for participants [89].

However, the long-term outcomes of rehabilitation need to be understood better. Two studies demonstrated an immediate significant increase to reading performance due to initial training sessions $[88,90]$; yet these changes plateaued or slightly waned over the course of subsequent sessions (very low quality evidence). Reasons for these effects were posited from reaching a maximum reading improvement during early training stages, to the concurrent decline in AMD vision from throughout rehabilitation. Another study found that CCTV by itself was more effective than repeated training sessions [35]. Moreover, a randomised control trial of three rehabilitation programs for newly diagnosed AMD patients found that participants experienced no more benefits to quality of life or ability to carry out everyday activities, from any specific rehabilitation model over another [37]. Instead, participants reported significantly worse scores on vision and health related quality of life questionnaires after twelve months - although these negative changes might not be due to the rehabilitation programs, but once again caused by the progression of AMD.

\section{Device comparisons}

Five studies comparing different low vision devices showed that all devices generated improvements on the measured outcome (low quality evidence) [35,76,92-94]. Two of these 
studies further indicated larger improvements with some devices (e.g. CCTV) than others (low quality evidence) [35,76]. Culham et al. [93] concluded that younger people with visual impairments can benefit from head-mounted devices (i.e. Jordy, Maxport) more than older people due to their familiarity with technology, but traditional low vision devices (i.e. magnifiers) can be just as effective. Performance-based measures demonstrated better reading experiences using a CCTV over less expensive low vision devices - which was complemented by participants preferences; but preferences became divided once cost was considered [76]. Similarly, Morrice et al. [94] concluded that an iPad was just as effective as a more expensive CCTV in improving reading speed.

Magnification, page navigation and ergonomic specifications

Studies evaluating magnification produced mixed findings: adjusting the magnification on low vision devices can have beneficial effects on reading rehabilitation [95], negative effects on reading speed [91], or no impact on reading rate (low quality evidence) [79]. A negative effect was that when participants increased a device's magnification, the time taken to read text passages also significantly increased [91]. There was evidence that simple low vision devices can be just as sufficient for reading, compared with high magnification capability devices [8]. Furthermore, the type of AMD (i.e. disciform vs atrophic) could influence the levels of magnification required [96].

Two studies surmised that using line guides and training improves reading ability for AMD individuals (very low quality evidence) [80,97]; although, retrace navigation can became more difficult with line guides, leading to reduced reading speed [97]. Regarding ergonomics, Watson et al. determined that functional interventions (i.e. desk height, stand tilt) significantly increased reading speed and decreased discomfort whilst using low vision devices (low quality evidence) [98]. 


\section{Discussion}

Most of the studies indicated that low vision devices have a positive impact on reading and other aspects of visual performance for AMD populations. Thus, utilising low vision devices can be an advantageous tool in managing daily life. Research indicates that people with AMD are likely to have preferences for certain devices due to financial, comfort or usability reasons, rather than pure performance-based findings [22,76]. This corresponds with conclusions made in a low vision rehabilitation review by Hooper et al. [24], who could not identify one device more effective than another due to the differing preferential needs of AMD patients.

The certainty of evidence reported in this review ranged from low to moderate, hindered by risks associated with methodological approaches and study designs. The insufficient provision of details reported in studies may have unintentionally courted bias. For example, it was often difficult to determine whether there were any additional interventions, other than low vision devices, that could have influenced study results. With more clarity in methods sections, risk could have been assessed better. The review by Binns et al. [28] also echoed this sentiment, suggesting that low vision research requires higher quality research.

\section{Simple vs Advanced Low Vision Devices}

Studies have shown that simple low vision devices (e.g., magnifiers) can be an effective vision enhancement device (low quality evidence). Previous reviews have found similar preferences and empirical evidence for magnifiers amongst visually impaired populations $[25,28]$. This finding has not changed despite the years and newer technology available, which speaks to the functionality of magnifying products. Many researchers concluded that these, and other simple low vision devices, delivered improvements to vision that were equal, or even superior, to the effectiveness of low vision devices with higher magnification capabilities $[8,76,94]$. Keeping in mind that the evidence for this was of low 
quality, the research suggests that newer technologies (e.g. iPad) may not currently provide more effective visual enhancement compared with traditional ones (e.g. hand-held magnifier).

Head-mounted devices, in particular, are being increasingly touted for the visually impaired, yet there lacks validated evidence within AMD populations. As demonstrated in Appendix B, many studies investigated magnifiers yet only four studies examined headmounted devices [34-37]. The scientific world may not have caught up with the changing technological world yet and possibly AMD research with these devices is still to come. However, equally feasible is that given the rate that technology evolves, by the time research is established on a low vision device, the technology itself is already outdated. As such, funding bodies may not want to invest in research that could have short-term practical applications.

There are additional studies investigating head-mounted devices (e.g., eSight) within combined visually impaired populations which show promising results, but were not included in this review because the studies did not specifically target AMD [99]. Specified studies on individualised populations are instead required because the needs for one visual impairment type differs substantially to another. For instance, retinitis pigmentosa preferentially affects the peripheral retina, leading to decreased night and peripheral vision [100]. A fundamental mechanism of any device suited to retinitis pigmentosa is amplifying light sources and expanding the field of view $[101,102]$. While these features will not hinder a person with AMD, there are limited benefits. In contrast, low vision devices marketed to AMD populations should, at a minimum, incorporate a magnifying component (e.g., high-powered lenses) into the underlying technology.

\section{Demographic of Low Vision Device Users}


An important consideration for device suitability is user age. The primary demographic of people affected by AMD is older adults - with the condition increasing in prevalence beyond 75 years old [2]. As people with AMD age and contend with equivalent declines in health and cognition, they may prefer the simplicity of hand magnifiers to the requirements of CCTV. Head-mounted device users have previously reported limited battery life, motion sickness or being distracted from their experience by difficulties with device controls $[103,104]$. These factors may account for suggested recommendations of simpler devices over complex ones.

These findings are also based upon the current generation of older adults, who did not grow up with touch screens, smartphones, and tablets. Older adults may not have integrated technology into their daily activities (e.g., banking, shopping, news) as much as younger people [105]. Rhodes noted that screen time is inversely proportional to the user age [106]. Children today are more flexible and adaptable to technology than preceding generations, because they are exposed to it from infancy. Thus, over time people with AMD may be more likely to overcome the barriers and deficits associated with embracing newer, technological low vision devices.

\section{Measures for Assessing Age Related Macular Degeneration}

The systematic review identified a wide range of measures for assessing vision, reading and other domains in AMD populations. The varied measures can make comparing study outcomes challenging, especially if measures are administered in different contexts. For example, the MNRead is a chart of continuous text designed to measure reading acuity [40]. Yet six studies utilised the MNRead as an assessment of vision rather than reading performance. The psychometric properties of the measures may also vary; therefore, some studies may have employed tools more sensitive than others at assessing the intended construct. This could be less of a problem for vision assessments as many charts are 
formatted to reflect LogMAR chart guidelines (e.g., Bailey-Lovie and ETDRS). The original LogMAR chart (i.e., Bailey-Lovie chart) was designed by the National Vision Research Institute of Australia, with optimal fonts, text sizes, spacing and number of letters, in order to set an industry standard for evaluating visual acuity [39]. The LogMAR chart has long been preferred to the original Snellen chart [42].

Regarding reading performance, there were 17 variations of materials presented to participants (see table 2). These included standardised materials (e.g., MNRead, International Reading Speed Tests) and also text from real items (e.g., bills, medicine bottles). The latter makes it difficult for researchers to replicate studies since the content is not always specified in the methodology. Then again, using real items provide a realistic representation of text that people with AMD struggle with daily, which makes the findings more generalisable for the public. Some instruments, like the Melbourne Low-Vision ADL Index and Very Low Vision Instrumental Activities of Daily Living [107,108], examine more than just reading (e.g., writing a check, threading a needle, pouring drinks). None of the studies in this review utilised these multi-domain instruments, but they have been administered in other studies to measure vision-related disability [99].

\section{The Implications of Home vs Laboratory Studies}

Beyond the specific use of measures, variability extends to the design of studies. Low vision devices were used within single event experiments in laboratories or clinics $[82,86]$, as well as at home or over long time periods $[35,84,90]$. The varying designs align with the need to assess outcomes in different environments - just as mentioned above, using real life items offers greater ecological validity. When participants take low vision devices home, they can practice with them during everyday activities they typically struggle with, whereas laboratory environments have more artificial tasks. Furthermore, home based studies might offer 
insights into long-term effects of low vision devices, beyond participants' initial engagement with them.

In this review, significant improvements to outcome measures (e.g., reading performance) were found during single laboratory studies and the early stages of long-term home studies (low-moderate quality evidence) [41,90,94]. However, for the latter studies, just like the rehabilitation studies discussed earlier, the positive effects of low vision devices plateaued or ebbed after a time (or as a result of AMD progression) [84,90]. This suggests a peak effect of low vision devices during initial device use. A finding like this is only revealed during experiments over weeks or months. Were recommendations to visually impaired communities based purely upon single laboratory studies, people with AMD may assume that low vision devices will always demonstrate increased changes. Generally, this could indicate that laboratory studies might not be the best predictor of real world effectiveness for low vision devices; however the degenerative nature of AMD makes it difficult to isolate device effects from the condition itself.

\section{Quality of Life for People with Age Related Macular Degeneration}

There are encouraging findings that low vision devices may improve quality of life, although current results are based on a small number of studies (low quality evidence). While vision-related outcomes appear to prosper from low vision devices, the self-report questionnaire results indicated that there were limited significant evidence for or against improvements to health domains beyond vision and reading. There are plenty of literature linking the impact of AMD on physical, social and psychological domains [7,10-13]; therefore as vision improves it was likely anticipated that low vision devices would also generate positive carry-over effects into these domains. A possible reason for the scarce evidence so far is that few studies investigated the long-term benefits of low vision devices beyond vision. 
Another reason could be that improvements from low vision devices may not have enough impact to make up for deficits elsewhere. Low vision devices are habitually used for stationary activities, such as reading, but have more limited applications in mobility-related tasks; although hands-free devices might be used to read text in public, such as street or shop names. Therefore, people with AMD may not experience benefits to activities of daily living beyond a few activities. It is acknowledged that for some individuals an improvement to a few may be enough; for example, people who enjoy reading. But, the continued struggles accomplishing mobile activities (e.g., cooking, shopping) may sustain people's negative feelings even when low vision devices are effective. The findings from the self-report questionnaires may not account for these other variables. Perhaps a combination of devices that incorporate static and mobile functionality would generate greater changes to quality of life if more components of daily living were made easier.

\section{Performance Testing and Self-reports}

[109]In the current review, no association was found between performance based measures and subjective ratings on the same outcomes $[77,80]$. Previous research has also revealed discrepancies between self-reported difficulty ratings and task performance for visually impaired participants [110,111]. For example, a study found inconsistencies between participant reported struggles reading newspapers and their actual reading speed on a standardised test [110]. Relying entirely on self-reports or performance testing alone may not be the best practice for evaluating the functional status of people with AMD. [111]

In the future, a mixture of methodological approaches [see 112] may capture a more informed picture of life with AMD . For example, researchers assessing stress levels experienced by people with AMD whilst shopping using low vision devices, could evaluate self-report scales, semi-structured interviews, and physiological measures. Wearable biometric technology can collect data on heart rate, skin conductance and physical 
movements, which in turn can be interpreted to reflect specific emotions [113]. These would be a useful addition to performance testing as they could endorse the feelings and behaviours of those with AMD [109]. Another endorsement can be elicited from the family, friends, or carers of patients, whose observations can validate the self-reported experiences.

\section{Limitations and Potential Biases in the Review Process}

This review was not prospectively registered, therefore there is no public record on the prior decisions made to guard against reporting biases. The allocation of devices, measures and outcomes to categorical groups may have introduced bias. However, these categorisations were carefully considered by two researchers to facilitate a simplified assessment of the findings. Furthermore, there could have been risks of bias in our selection criteria. By directing the review on "age-related" macular degeneration, studies were excluded with samples of alternative macular degeneration populations (e.g., Charles Bonnet Syndrome). The different presentation of symptomology and, resultingly, the different management and supportive care approaches required, are what prompted this decision. Nevertheless, we recognise there could be low vision devices that might offer similar visual improvements to all types of macular degeneration.

Another selection criteria limitation was the exclusion of surgical implants (e.g., visual prosthetics or intraocular devices). While not included due to the reviews focus on external low vision devices, the value of implants cannot be discounted. For example, intraocular devices can significantly improve visual acuity, reading speed and quality of life, demonstrating both post-operative and long-terms gains [114]. In one study, patients bestcorrected near and distance visual acuity significantly improved twelve months after a telescopic optical device was implanted [115]; patients also reported significant improvements to functional vision and quality of life. Unfortunately, the benefits of implants 
come with associated risks of eye surgery. As assessing surgical risks are not within the scope of this review, interested patients should review these elsewhere [116].

The role of rehabilitation and training programs on low vision devices was discussed in this review, but the impact of specific rehabilitation programs was not. For example, eccentric viewing training was adopted by several studies in this review [35-36], but the implications of this type of training on those with AMD was not explored. While this decision could be construed as bias, analysing the effects of each type of rehabilitation program would have exceeded the parameters of this review. In fact, examining the impact of rehabilitation programs on AMD populations could be a specified review itself. Finally, the choice of reporting guidelines, PRISMA, could also be biased. PRISMA was chosen as it is the 'gold standard' for reporting systematic reviews in health sciences. However, the guidelines are slanted towards quantitative results and may therefore neglect important complementary findings deriving from qualitative assessments.

\section{Conclusion}

Considerations for future low vision devices should delve deeper into how devices can target various manifestations of AMD. Blurred vision, central scotomas, depth impairment, light sensitivity, and reduced contrast sensitivity can all be AMD symptoms. Patients may experience one of these, or all. While magnification remains a crucial component in overcoming deficits caused by AMD, technology developers might consider how their products could address these other aspects. Another consideration is the cost of low vision devices. Unless companies can find ways to minimise the price of expensive devices, they may be inaccessible for many visually impaired people. Cost effectiveness was previously examined by Binns et al. [28] who concluded there was limited evidence on the cost benefits of low vision services. 
The current state of research suggests there is a preference for simpler low vision devices rather than advanced technology. A caveat to this is the of lack of high-quality studies examining newer technologies for people with AMD. Until such a time when headmounted devices or CCTV are more financially accessible or have overcome usability challenges faced by older adults with AMD, traditional magnifiers are likely to remain the preferred methods for vision enhancement.

Overall, this review has demonstrated that low vision devices have a significant effect on improving participant outcomes, primarily vision and reading performance. However, more research yielding high-quality evidence needs to be conducted. Many organisations advocate for AMD patients to receive financial support to buy low vision devices. But governments and disability insurers often require rigorous scientific evidence on the effectiveness of low vision devices prior to funding provision. Therefore, the continued examination of low vision devices, using high-quality research methods, will contribute substantially towards evidence-based policy changes.

Word count: 6,129 


\section{Funding}

AM is supported by the Australian Government Research Training Program

Scholarship and TL is funded by a National Health and Medical Research Council (NHMRC)

Dementia Research Leadership Fellowship (GNT1136269).

\section{Disclosure of interest}

There were no sources of conflict. 


\section{References}

1. Wong WL, Su X, Li X, et al. Global prevalence of age-related macular degeneration and disease burden projection for 2020 and 2040: a systematic review and metaanalysis. Lancet Glob Health. 2014 Feb;2(2):e106-16.

2. Jonas JB, Cheung CMG, Panda-Jonas S. Updates on the Epidemiology of AgeRelated Macular Degeneration. Asia Pac J Ophthalmol (Phila). 2017 NovDec;6(6):493-497.

3. Tong B, Duff D, Mullen G, et al. A snapshot of blindness and low vision services in Australia 2020 [cited 2019 December 12]. Available from:

https://www.vision2020australia.org.au/wp-content/uploads/2019/06/A-snapshot-ofblindness-and-low-vision-services-in-Australia-1.pdf

4. Spooner KL, Mhlanga CT, Hong TH, et al. The burden of neovascular age-related macular degeneration: a patient's perspective. Clin Ophthalmol. 2018;12:2483-2491.

5. Lim LS, Mitchell P, Seddon JM, et al. Age-related macular degeneration. Lancet. 2012 May 5;379(9827):1728-38.

6. Taylor DJ, Hobby AE, Binns AM, et al. How does age-related macular degeneration affect real-world visual ability and quality of life? A systematic review. BMJ Open. 2016 Dec 2;6(12):e011504.

7. Lane J, Rohan EMF, Sabeti F, et al. Impacts of impaired face perception on social interactions and quality of life in age-related macular degeneration: A qualitative study and new community resources. PLoS One. 2018;13(12):e0209218.

8. Nguyen NX, Weismann M, Trauzettel-Klosinski S. Improvement of reading speed after providing of low vision aids in patients with age-related macular degeneration. Acta Ophthalmol. 2009 Nov;87(8):849-53. 
9. Wood JM, Lacherez P, Black AA, et al. Risk of falls, injurious falls, and other injuries resulting from visual impairment among older adults with age-related macular degeneration. Invest Ophthalmol Vis Sci. 2011 Jul 7;52(8):5088-92.

10. Berman K, Brodaty H. Psychosocial effects of age-related macular degeneration. Int Psychogeriatr. 2006 Sep;18(3):415-28.

11. Cimarolli VR, Casten RJ, Rovner BW, et al. Anxiety and depression in patients with advanced macular degeneration: current perspectives. Clin Ophthalmol. 2016;10:5563.

12. Williams RA, Brody BL, Thomas RG, et al. The psychosocial impact of macular degeneration. Arch Ophthalmol. 1998 Apr;116(4):514-20.

13. Yuzawa M, Fujita K, Tanaka E, et al. Assessing quality of life in the treatment of patients with age-related macular degeneration: clinical research findings and recommendations for clinical practice. Clin Ophthalmol. 2013;7:1325-32.

14. Poley PR, Stapleton WM, Qui F, et al. Age-related macular degeneration: review of current treatments [Article]. Expert Review of Ophthalmology. 2011 2011/04;6:195.

15. Mitchell J, Bradley C. Quality of life in age-related macular degeneration: a review of the literature. Health Qual Life Outcomes. 2006 Dec 21;4:97.

16. Vision Australia. Vision Australia shop 2020 [cited 2020 May 20]. Available from: https://shop.visionaustralia.org/

17. Brunnstrom G, Sorensen S, Alsterstad K, et al. Quality of light and quality of life--the effect of lighting adaptation among people with low vision. Ophthalmic Physiol Opt. 2004 Jul;24(4):274-80.

18. Minto H, Butt IA. Low vision devices and training. Community Eye Health. 2004;17(49):6-7. 
19. Moshtael H, Aslam T, Underwood I, et al. High Tech Aids Low Vision: A Review of Image Processing for the Visually Impaired. Transl Vis Sci Technol. 2015 Aug;4(4):6.

20. Deemer AD, Bradley CK, Ross NC, et al. Low Vision Enhancement with Headmounted Video Display Systems: Are We There Yet? Optom Vis Sci. 2018 Sep;95(9):694-703.

21. Wolffsohn JS, Peterson RC. A review of current knowledge on Electronic Vision Enhancement Systems for the visually impaired. Ophthalmic Physiol Opt. 2003 Jan;23(1):35-42.

22. Juan M-C, García-García I, Mollá R, et al. Users' Perceptions Using Low-End and High-End Mobile-Rendered HMDs: A Comparative Study. Computers. 2018;7(1):15.

23. Hassell JB, Lamoureux EL, Keeffe JE. Impact of age related macular degeneration on quality of life. Br J Ophthalmol. 2006 May;90(5):593-6.

24. Hooper P, Jutai JW, Strong G, et al. Age-related macular degeneration and low-vision rehabilitation: a systematic review. Can J Ophthalmol. 2008 Apr;43(2):180-7.

25. Virgili G, Acosta R, Bentley SA, et al. Reading aids for adults with low vision. Cochrane Database Syst Rev. 2018 Apr 17;4:CD003303.

26. Hamade N, Hodge WG, Rakibuz-Zaman M, et al. The Effects of Low-Vision Rehabilitation on Reading Speed and Depression in Age Related Macular Degeneration: A Meta-Analysis. PLoS One. 2016;11(7):e0159254.

27. Heravian Shandiz J, Heydarian S, Mahjoob M, et al. Using low vision aids in improving the quality of life in patients with age related macular degeneration: A review of the literature. 2016 01/01;25:376-392.

28. Binns AM, Bunce C, Dickinson C, et al. How effective is low vision service provision? A systematic review. Surv Ophthalmol. 2012 Jan-Feb;57(1):34-65. 
29. Liberati A, Altman DG, Tetzlaff J, et al. The PRISMA statement for reporting systematic reviews and meta-analyses of studies that evaluate healthcare interventions: explanation and elaboration. BMJ. 2009 Jul 21;339:b2700.

30. Tufanaru C, Munn Z, Aromataris E, et al. Chapter 3: systematic reviews of effectiveness. 2017. In: Joanna Briggs institute reviewer's manual [Internet]. The Joanna Briggs institute. Available from: https://reviewersmanual.joannabriggs.org/.

31. McHugh ML. Interrater reliability: the kappa statistic. Biochem Med (Zagreb). 2012;22(3):276-82.

32. Guyatt GH, Oxman AD, Vist GE, et al. GRADE: an emerging consensus on rating quality of evidence and strength of recommendations. BMJ. 2008 Apr 26;336(7650):924-6.

33. Pollock A, Farmer SE, Brady MC, et al. An algorithm was developed to assign GRADE levels of evidence to comparisons within systematic reviews. J Clin Epidemiol. 2016 Feb;70:106-10.

34. Eklund K, Dahlin-Ivanoff S. Low vision, ADL and hearing assistive device use among older persons with visual impairments. Disabil Rehabil Assist Technol. 2007 Nov;2(6):326-34.

35. Leat SJ, Si FF, Gold D, et al. The Experience of a Randomized Clinical Trial of Closed-Circuit Television versus Eccentric Viewing Training for People with AgeRelated Macular Degeneration. Journal of Visual Impairment \& Blindness. 2017 2017/07/01;111(4):354-368.

36. Nilsson UL. Visual rehabilitation with and without educational training in the use of optical aids and residual vision. A prospective study of patients with advanced agerelated macular degeneration. Clinical Vision Science. 1990;6:3-10. 
37. Reeves BC, Harper RA, Russell WB. Enhanced low vision rehabilitation for people with age related macular degeneration: a randomised controlled trial. Br J Ophthalmol. 2004 Nov;88(11):1443-9.

38. Ferris FL, 3rd, Kassoff A, Bresnick GH, et al. New visual acuity charts for clinical research. Am J Ophthalmol. 1982 Jul;94(1):91-6.

39. Bailey IL, Lovie JE. New design principles for visual acuity letter charts. Am J Optom Physiol Opt. 1976 Nov;53(11):740-5.

40. Mansfield JS, Ahn SJ, Legge GE, et al. A new reading-acuity chart for normal and low vision. Ophthalmic and Visual Optics/Noninvasive Assessment of the Visual System Technical Digest. 1993;3:232-235.

41. Frennesson C, Jakobsson P, Nilsson UL. A computer and video display based system for training eccentric viewing in macular degeneration with an absolute central scotoma. Doc Ophthalmol. 1995;91(1):9-16.

42. Snellen H. Probebuchstaben zur bestimmung der sehschärfe (Sample letters to determine visual acuity). Van de Weijer: Utrecht; 1862.

43. Hyvarinen L, Nasanen R, Laurinen P. New visual acuity test for pre-school children. Acta Ophthalmol (Copenh). 1980 Aug;58(4):507-11.

44. Monoyer F. Monoyer chart [Vision chart]. Ferdinand Monoyer; 1872.

45. Topcon. ACP-8EM, Chart projector. Topcon; 2018.

46. Trauzettel-Klosinski S, Dietz K, Group IRS. Standardized assessment of reading performance: the New International Reading Speed Texts IReST. Invest Ophthalmol Vis Sci. 2012 Aug 13;53(9):5452-61.

47. Silverstone B, Lane MA, Rosenthal B, et al. The lighthouse handbook on vision impairment and vision rehabilitation: two volume set. USA: Oxford University Press; 2000. 
48. Bailey IL, Lovie JE. The design and use of a new near-vision chart. Am J Optom Physiol Opt. 1980 Jun;57(6):378-87.

49. Jaeger E. Schrift-scalen (font scales). Victor Masson, Paris: Seidel und Sohn Wien; 1856.

50. Maclure GM. Reading type for children. Br J Ophthalmol. 1980 Jun;64(6):461-5.

51. Oxford University Press. Oxford progressive English readers 2020 [cited 2020 May 21]. Available from: https://oup.com.pk/school-textbooks/english/englishreader/oxford-progressive-english-readers.html

52. Sloan LL, Brown DJ. Reading Cards for Selection of Optical Aids for the Partially Sighted. American Journal of Ophthalmology. 1963 1963/06/01/;55(6):1187-1199.

53. Sussex Vision. Vocational near vision test type 2020 [cited 2020 May 26]. Available from: https://www.sussex-vision.co.uk/vocational-near-vision-test-type

54. Bailey IL, editor Prescribing magnification: strategies for improving accuracy and consistency. Proceedings of the international symposium on low vision. Low vision. Principles and application; 1986.

55. Wu DZ, Chang FX, Wu L, et al. Visual rehabilitation in low vision patients with agerelated macular degeneration. Yan Ke Xue Bao. 1991 Sep;7(3):143-5.

56. Radner W, Willinger U, Obermayer W, et al. [A new reading chart for simultaneous determination of reading vision and reading speed]. Klin Monbl Augenheilkd. 1998 Sep;213(3):174-81.

57. Wierderholt JL, Bryant BR. Gray oral reading tests-4th edition. Circle Pines: American Guidance Service; 2001.

58. Watson GR, Wright V. The Morgan low vision reading comprehension assessment. Lilburn: Bear Consultants; 1996. 
59. Neale MD, McKay MF, Barnard J. Neale analysis of reading ability, 3rd ed. Australian Council for Educational Research: Camberwell; 1999.

60. Folstein MF, Folstein SE, McHugh PR. "Mini-mental state". A practical method for grading the cognitive state of patients for the clinician. J Psychiatr Res. 1975 Nov;12(3):189-98.

61. Nasreddine ZS, Phillips NA, Bédirian V, et al. The Montreal Cognitive Assessment, MoCA: a brief screening tool for mild cognitive impairment. J Am Geriatr Soc. 2005 Apr;53(4):695-9.

62. Pfeiffer E. A short portable mental status questionnaire for the assessment of organic brain deficit in elderly patients. J Am Geriatr Soc. 1975 Oct;23(10):433-41.

63. Sheikh JI, Yesavage JA. Geriatric Depression Scale (GDS): Recent evidence and development of a shorter version. Clinical Gerontologist: The Journal of Aging and Mental Health. 1986;5(1-2):165-173.

64. Radloff LS. The CES-D Scale: A Self-Report Depression Scale for Research in the General Population. Applied Psychological Measurement. 1977 1977/06/01;1(3):385401.

65. Zigmond AS, Snaith RP. The hospital anxiety and depression scale. Acta Psychiatr Scand. 1983 Jun;67(6):361-70.

66. Owsley C, Stalvey B, Wells J, et al. Older drivers and cataract: driving habits and crash risk. J Gerontol A Biol Sci Med Sci. 1999 Apr;54(4):M203-11.

67. Ware JE, Jr., Sherbourne CD. The MOS 36-item short-form health survey (SF-36). I. Conceptual framework and item selection. Med Care. 1992 Jun;30(6):473-83.

68. Mangione CM, Lee PP, Gutierrez PR, et al. Development of the 25-item National Eye Institute Visual Function Questionnaire. Arch Ophthalmol. 2001 Jul;119(7):1050-8. 
69. Dodds AG, Flannigan $\mathrm{H}, \mathrm{Ng}$ L. The Nottingham Adjustment Scale: a validation study. Int J Rehabil Res. 1993 Sep;16(3):177-84.

70. Day H, Jutai J. Measuring the psychosocial impact of assistive devices: the PIADS. Canadian Journal of Rehabilitation. 1996;9(2):159-168.

71. Harper R, Doorduyn K, Reeves B, et al. Evaluating the outcomes of low vision rehabilitation. Ophthalmic Physiol Opt. 1999 Jan;19(1):3-11.

72. Crichton N. Visual analogue scale (VAS). J Clin Nurs. 2001;10(5):706-6.

73. Massof RW, Ahmadian L, Grover LL, et al. The Activity Inventory: an adaptive visual function questionnaire. Optom Vis Sci. 2007 Aug;84(8):763-74.

74. Frost NA, Sparrow JM, Durant JS, et al. Development of a questionnaire for measurement of vision-related quality of life. Ophthalmic Epidemiol. 1998 Dec;5(4):185-210.

75. Hart PM, Chakravarthy U, Stevenson MR, et al. A vision specific functional index for use in patients with age related macular degeneration. Br J Ophthalmol. 1999 Oct;83(10):1115-20.

76. Goodrich GL, Kirby J. A comparison of patient reading performance and preference: optical devices, handheld CCTV (Innoventions Magni-Cam), or stand-mounted CCTV (Optelec Clearview or TSI Genie). Optometry. 2001 Aug;72(8):519-28.

77. Tejeria L, Harper RA, Artes PH, et al. Face recognition in age related macular degeneration: perceived disability, measured disability, and performance with a bioptic device. Br J Ophthalmol. 2002 Sep;86(9):1019-26.

78. Walker R, Bryan L, Harvey H, et al. The value of Tablets as reading aids for individuals with central visual field loss: an evaluation of eccentric reading with static and scrolling text. Ophthalmic Physiol Opt. 2016 Jul;36(4):459-64. 
79. Cheong AC, Lovie-Kitchin JE, Bowers AR. Determining magnification for reading with low vision. Clin Exp Optom. 2002 Jul;85(4):229-37.

80. Bowers A, Cheong AM, Lovie-Kitchin JE. Reading with optical magnifiers: page navigation strategies and difficulties. Optom Vis Sci. 2007 Jan;84(1):9-20.

81. Watson LM, Strang NC, Scobie F, et al. Image jitter enhances visual performance when spatial resolution is impaired. Invest Ophthalmol Vis Sci. 2012 Sep 6;53(10):6004-10.

82. Calabrese A, Aguilar C, Faure G, et al. A Vision Enhancement System to Improve Face Recognition with Central Vision Loss. Optom Vis Sci. 2018 Sep;95(9):738-746.

83. Rishi P, Rishi E, Maitray A, et al. Hospital anxiety and depression scale assessment of 100 patients before and after using low vision care: A prospective study in a tertiary eye-care setting. Indian J Ophthalmol. 2017 Nov;65(11):1203-1208.

84. Huber JG, Jutai JW, Strong JG, et al. The Psychosocial Impact of Closed-Circuit Televisions on Persons with Age-Related Macular Degeneration. Journal of Visual Impairment \& Blindness. 2008 2008/11/01;102(11):690-701.

85. Decarlo DK, McGwin G, Jr., Searcey K, et al. Use of prescribed optical devices in age-related macular degeneration. Optom Vis Sci. 2012 Sep;89(9):1336-42.

86. Moshtael H, Tooth C, Nuthmann A, et al. Dynamic text presentation on smart glasses: A pilot evaluation in age-related macular degeneration. British Journal of Visual Impairment. 2019 2020/01/01;38(1):24-37.

87. Gill K, Mao A, Powell AM, et al. Digital reader vs print media: the role of digital technology in reading accuracy in age-related macular degeneration. Eye (Lond). 2013 May;27(5):639-43.

88. Nilsson UL, Nilsson SE. Rehabilitation of the visually handicapped with advanced macular degeneration. A follow-up study at the Low Vision Clinic, Department of 
Ophthalmology, University of Linköping. Doc Ophthalmol. 1986 May 15;62(4):34567.

89. Khan SA, Das T, Kumar SM, et al. Low vision rehabilitation in patients with agerelated macular degeneration at a tertiary eye care centre in southern India. Clin Exp Ophthalmol. 2002 Dec;30(6):404-10.

90. Cheong AM, Lovie-Kitchin JE, Bowers AR, et al. Short-term in-office practice improves reading performance with stand magnifiers for people with AMD. Optom Vis Sci. 2005 Feb;82(2):114-27.

91. Nguyen NX, Trauzettel-Klosinski S. Effectiveness of Magnifying Low Vision Aids in Patients with Age-Related Macular Degeneration. Neuro-Ophthalmology. 2009;33(3):115-119.

92. Ballinger R, Lalle P, Maino J, et al. Veterans Affairs Multicenter Low Vision Enhancement System (LVES) study: clinical results. Report 1: effects of manualfocus LVES on visual acuity and contrast sensitivity. Optometry. 2000 Dec;71(12):764-74.

93. Culham LE, Chabra A, Rubin GS. Clinical performance of electronic, head-mounted, low-vision devices. Ophthalmic Physiol Opt. 2004 Jul;24(4):281-90.

94. Morrice E, Johnson AP, Marinier JA, et al. Assessment of the Apple iPad as a lowvision reading aid. Eye (Lond). 2017 Jun;31(6):865-871.

95. Amore FM, Silvestri V, Turco S, et al. Rehabilitative approach in patients with ring scotoma. Can J Ophthalmol. 2013 Oct;48(5):420-6.

96. Virtanen P, Laatikainen L. Primary success with low vision aids in age-related macular degeneration. Acta Ophthalmol (Copenh). 1991 Aug;69(4):484-90.

97. Cheong AM, Bowers AR, Lovie-Kitchin JE. Does a line guide improve reading performance with stand magnifiers? Optom Vis Sci. 2009 Sep;86(9):E1078-85. 
98. Watson GR, Ramsey V, De l'Aune W, et al. Ergonomic Enhancement for Older Readers with Low Vision. Journal of Visual Impairment \& Blindness. 2004 2004/04/01;98(4):228-240.

99. Wittich W, Lorenzini MC, Markowitz SN, et al. The Effect of a Head-mounted Low Vision Device on Visual Function. Optom Vis Sci. 2018 Sep;95(9):774-784.

100. Hartong DT, Berson EL, Dryja TP. Retinitis pigmentosa. Lancet. 2006 Nov 18;368(9549):1795-809.

101. Mancil RM, Mancil GL, King E, et al. Improving nighttime mobility in persons with night blindness caused by retinitis pigmentosa: A comparison of two low-vision mobility devices. J Rehabil Res Dev. 2005 Jul-Aug;42(4):471-86.

102. Malik U. Top 3 retinitis pigmentosa glasses 2020 [cited 2020 April 2]. Available from: https://irisvision.com/top-retinitis-pigmentosa-glasses/

103. Moss JD, Muth ER. Characteristics of head-mounted displays and their effects on simulator sickness. Hum Factors. 2011 Jun;53(3):308-19.

104. Lorenzini MC, Hämäläinen AM, Wittich W. Factors related to the use of a headmounted display for individuals with low vision. Disabil Rehabil. 2019 Dec 28:1-15.

105. Brohl C, Rasche P, Jablonski J, et al. Desktop pc, tablet pc, or smartphone? An analysis of use preferences in daily activities for different technology generations of a worldwide sample. In: Zhou J, Salvendy G, editors. Human Aspects of IT for the Aged Population. Acceptance, Communication and Participation: Cham: Springer; 2018. p. 3-20.

106. Rhodes A. Screen time and kids: what's happening in our homes? 2017 [cited 2020 April 2]. Available from: https://www.rchpoll.org.au/wpcontent/uploads/2017/06/ACHP-Poll7_Detailed-Report-June21 
107. Haymes SA, Johnston AW, Heyes AD. The development of the Melbourne lowvision ADL index: a measure of vision disability. Invest Ophthalmol Vis Sci. 2001 May;42(6):1215-25.

108. Finger RP, McSweeney SC, Deverell L, et al. Developing an instrumental activities of daily living tool as part of the low vision assessment of daily activities protocol. Invest Ophthalmol Vis Sci. 2014 Nov 25;55(12):8458-66.

109. Dang J, King KM, Inzlicht M. Why Are Self-Report and Behavioral Measures Weakly Correlated? Trends Cogn Sci. 2020 Apr;24(4):267-269.

110. Friedman SM, Munoz B, Rubin GS, et al. Characteristics of discrepancies between self-reported visual function and measured reading speed. Salisbury Eye Evaluation Project Team. Invest Ophthalmol Vis Sci. 1999 Apr;40(5):858-64.

111. Hickson L, Lind C, Worrall L, et al. Hearing and Vision in Healthy Older Australians: Objective and Self-Report Measures. Advances in Speech Language Pathology. 1999 1999/01/01;1(2):95-105.

112. Creswell JW, Klassen AC, Clark VLP, et al. Best Practices for Mixed Methods Research in the Health Sciences. 2011.

113. Hayano J, Tanabiki T, Iwata S, et al., editors. Estimation of Emotions by Wearable Biometric Sensors Under Daily Activities. 2018 IEEE 7th Global Conference on Consumer Electronics (GCCE); 2018 9-12 Oct. 2018.

114. Grzybowski A, Wang J, Mao F, et al. Intraocular vision-improving devices in agerelated macular degeneration. Ann Transl Med. 2020 Nov;8(22):1549.

115. Hudson HL, Lane SS, Heier JS, et al. Implantable miniature telescope for the treatment of visual acuity loss resulting from end-stage age-related macular degeneration: 1-year results. Ophthalmology. 2006 Nov;113(11):1987-2001. 
116. Lansingh VC, Eckert KA, Strauss G. Benefits and risks of immediately sequential bilateral cataract surgery: a literature review. Clin Exp Ophthalmol. 2015 SepOct;43(7):666-72. 